\title{
MAGEA6 positively regulates MSMO1 and promotes the migration and invasion of oesophageal cancer cells
}

\author{
MANYU LIU, JINTAO LI, YANGJUNQI WANG, MALIHA GHAFFAR, \\ YISHU YANG, MINGLIAN WANG and CHANGSHUO LI
}

\begin{abstract}
Beijing Key Laboratory of Environmental and Viral Oncology, Faculty of Environment and Life, Beijing University of Technology, Beijing 100124, P.R. China
\end{abstract}

Received November 17, 2020; Accepted August 2, 2021

DOI: $10.3892 /$ etm.2022.11127

\begin{abstract}
The melanoma antigen gene family A (MAGEA) family of proteins comprises of cancer-testis antigens that are highly expressed in a number of tumours but are minimally expressed in normal cells. Due to its expression characteristics, this protein family has become a popular target for anti-cancer drugs and immunotherapy research over recent years. Although, elevated expression levels of MAGEA6 has been found in different types of tumours, there remains to be insufficient information on the function of MAGEA6 and its associated gene regulation pathways. The present study used Transwell, Cell Counting Kit- 8 and wound healing assays to analyse the effects of MAGEA6 on Eca109 cell invasion, migration and proliferation. The main functions and pathways involved in MAGEA6 were predicted by Illumina Hiseq screening for mutually regulated genes and core genes. Eca109 cell line with a high expression of MAGEA6 was a stable cell line obtained by transfection in the early stage, and this cell line was used in subsequent experiments. Transcriptome sequencing was performed on this cell line and the Eca109 cell line that normally expressed MAGEA6. It was revealed that a high expression of MAGEA6 conferred a significant stimulating effect on cell proliferation whilst also significantly increasing cell invasion and migration. Transcriptomic analysis identified 14 differentially expressed genes and 13 core regulatory genes closely associated with MAGEA6 expression regulation, such as methylsterol monooxygenase 1 (MSMO1). The present study suggest that MAGEA6 positively regulated MSMO1 expression, which may serve an oncogenic role in cells through this regulatory effect. Overall, this provided a novel route of
\end{abstract}

Correspondence to: Dr Jintao Li, Beijing Key Laboratory of Environmental and Viral Oncology, Faculty of Environment and Life, Beijing University of Technology, 100 Pingleyuan, Chaoyang, Beijing 100124, P.R. China

E-mail: 1jt2008@bjut.edu.cn

Key words: oesophageal cancer cells, melanoma antigen family A 6, transcriptome analysis, methylsterol monooxygenase 1, RNA polymerase II investigation for an in-depth study of the regulatory function of MAGEA6.

\section{Introduction}

Melanoma antigen gene family A (MAGEA) genes are highly expressed in different types of cancer, such as melanoma, esophageal cancer and gastric cancer (1). Van der Bruggen first discovered human proteins, and discovered that the melanoma-associated antigen was encoded by the MAGEAl gene (2). After the discovery of MAGEA, other MAGE family members, MAGE-B, C, D, E, F, G, H, L and Necdin, were also discovered (2).

There are two types of MAGEs based on tissue expression. Both types of MAGE (type I and II) have a MAGE homology domain, which contains $\sim 170$ amino acids $(2,3)$. MAGE-I of the $M A G E$ gene family is expressed in human tumour cells, such as melanoma, esophageal cancer, gastric cancer, but not in normal human adult tissues, except in the germ line of males (2). There are 12 members in the MAGE-A family, which includes type I MAGE proteins encoded by chromosome Xq28 in humans (2). MAGE proteins are candidates for vaccine development. MAGE is a target protein for the treatment of many malignant diseases and the results of a previous study demonstrated the development of a potent cytotoxic T-lymphocyte epitope to elicit a desirable immune response against carcinogenic melanoma-associated antigen-A11 (3). Although their expression has been measured in a number of tumour cell types, such as melanoma, esophageal cancer, gastric cancer, to the best of our knowledge, their role in disease pathogenesis has not been explored in detail (4). At present, the research on its mechanism is not perfect, and the mechanism in many diseases is still unclear, such as melanoma, esophageal cancer, gastric cancer, etc.

All members of the MAGE family encode proteins that share a strong homology with each other, where MAGEA6 and MAGEA3 have the highest homology (98\%). However, in tumour tissues such as cervical cancer tissues, there is a negative correlation between the expression of MAGEA6/MAGEA3 and clinical staging $(4,5)$. These two MAGEs may therefore serve as biomarkers for the in situ prediction of early precancerous lesions (4). A recent study has focused on the role of MAGEA3 in cervical cancer, which has been hypothesised to 
participate in a number of functional processes. The overexpression of MAGEA3 significantly promoted the proliferation of SiHa cells in vitro and in vivo, increased the proportion of cells in S-phase of the cell cycle and inhibited apoptosis (5). In addition, MAGEA3 downregulation was revealed to inhibit HeLa cell proliferation, block cell cycle progression in the $\mathrm{G}_{1}$ phase and promote cell apoptosis (5). Studies into the underlying mechanism found that MAGEA3 interacts with KRAB domain-associated protein 1 (KAP1) to inhibit the transcriptional activity of $\mathrm{p} 53$, thereby inhibiting the expression of p53-mediated cell cycle (p21 and Cyclin D1) and apoptosis (Bax, Bcl-2 and Bcl-2 binding component 3)-related genes (5). These results suggest that MAGEA3 contributes to the proliferation of cervical cancer cells and tumour growth, in turn serving an oncogenic role, by regulating the KAP1/p53 signalling pathway (5). At present, to the best of our knowledge, there have only been a small number of studies on MAGEA6. It has been previously revealed that MAGEA6 mediates the survival of human glioma cells by targeting 5'AMP-activated protein kinase (AMPK) $\alpha 1$, mediating AMPK signalling to inhibit the maintenance and self-renewal ability of glioma cells (6). The MAGEA6 gene has a total of three exon regions and is located at the end of the long arm of the X chromosome Xq28 $(6,7)$. MAGEA6 is frequently expressed and reactivated in a number of human cancer cells, such as human glioma and esophageal cancer. (7). A previous study by Pineda et al (7) demonstrated that the MAGEA6/KAP1 complex is a cancer-specific ubiquitin ligase that only degrades AMPK $\alpha 1$ in human glioma cells and gastric cancer cells. In addition, knocking down MAGEA6 expression inhibited the growth of severe combined immunodeficiency mice-transplanted tumours and inhibited the proliferation of primary human glioma cells in vivo (7).

A previous study measured the expression level of MAGEA6 in oesophageal squamous cell carcinoma (ESCC) cells and oesophageal adenocarcinoma tissues. The results indicated that MAGEA6 is highly transcribed and expressed in the development of ESCC and may therefore serve as a novel biomarker for the diagnosis or treatment of ESCC (8). In vitro assays were also performed to investigate the biological function of MAGEA6 in ESCC, which may help to understand its role in this disease and the factors contributing to its upregulation. It is hypothesised that for individuals who are prone to developing specific types of cancer, their natural cellular immunity against MAGEA6 may serve a role in the development of cancer. Specifically, cellular immunity may also protect against the recurrence of MAGEA6-associated disease, such as human glioma cells, in addition to tumour growth $(8,9)$. Therefore, the function of MAGEA6 and its regulation need to be studied in depth.

\section{Materials and methods}

Cell culture and screening. The ESCC cell lines Eca109, EC9706, KYSE150, and Hacat cell line were obtained from the Zeng Academician Laboratory of the Virus Prevention and Control Institute; Chinese Center for Disease Control and Prevention. Cells were cultured in DMEM (HyClone; Cytiva) supplemented with 10\% FBS (Gibco; Thermo Fisher Scientific, Inc.) and maintained at $37^{\circ} \mathrm{C}$ with $5 \% \mathrm{CO}_{2}$ in a humidified incubator (10).
Vector construction and selection of stable cell lines. At the logarithmic phase, Eca109 cells were digested with trypsin at $37^{\circ} \mathrm{C}$ for $3 \mathrm{~min}$, and were inoculated into a six-well at $2 \times 10^{5}$ cells $/ \mathrm{ml}$. Transfection was performed when cells reached $60-70 \%$ confluence. The plate was placed in a humidified incubator overnight at $37^{\circ} \mathrm{C}$ with $5 \% \mathrm{CO}_{2}$. The virus was thawed on the day of transfection and $1 \mathrm{ml}$ complete medium was added. The mixture was gently pipetted and $2 \mu \mathrm{g}$ polybrene-containing virus solution (Invitrogen; Thermo Fisher Scientific, Inc.) was added to Eca109 cells. The cells were placed in a humidified incubator at $37^{\circ} \mathrm{C}$ with $5 \% \mathrm{CO}_{2}$. After $48 \mathrm{~h}$ of exposure, the aforementioned medium was changed to a selection medium, which contained $2 \mu \mathrm{g} / \mathrm{ml}$ puromycin (Thermo Fisher Scientific, Inc.). The medium was changed every 3 days for 2 weeks and the cells that died were not deemed stable with puromycin resistance. Lentivirus-mediated MAGEA6-overexpressing Eca109 cells were constructed (Eca109-MAGEA6-3.1). The lentiviral plasmid backbone used was pcDNA ${ }^{\mathrm{TM}} 3.1(+$; Thermo Fisher Scientific, Inc.), and the interim cell line used was the 293T cell line obtained from the Chinese Center for Disease Control and Prevention. The quantity of lentiviral plasmid used for transfection was $2 \mu \mathrm{g}$, incubated for $12 \mathrm{~h}$ overnight in an incubator at $37^{\circ} \mathrm{C}$ and $5 \% \mathrm{CO}_{2}$. The same method was used to obtain cells transfected with an empty carrier (Eca109-3.1).

RNA sequencing. For high-throughput sequencing, cultured Eca109-3.1 cells and Eca109-MAGEA6-3.1 cells were handed over to Beijing IgeneCode Biotech Co., Ltd. to perform the sequencing experiments. A total of $2 \mathrm{ml}$ Trizol ${ }^{\circledR}$ reagent (Invitrogen; Thermo Fisher Scientific, Inc.) was added to extract RNA from cells and digesting the DNA with DNase I (Invitrogen; Thermo Fisher Scientific, Inc.), the consequent RNA samples were tested. After the high-throughput detection results met the requirements, the database was built. An Agilent 2100 Bioanalyzer (Agilent Technologies, Inc.) was used to detect RNA concentration, Rin value, $28 \mathrm{~S} / 18 \mathrm{~S}$ ratio and fragment size to determine RNA integrity. The purity of RNA (optical density ratio of 260/280) was detected by Nanodrop. After the samples were qualified, the library was constructed according to the following steps, according to the manufacturer's protocol: i) Oligo d(T)-loaded magnetic beads were used to enrich the eukaryotic mRNA; ii) the fragmentation buffer was added to break the mRNA into short fragments; iii) using Eca109 mRNA as template, the first cDNA strand was synthesized with random hexamers before the second cDNA strand was synthesized by adding buffer, dNTPs, RNase H and DNA polymerase; iv) the purified double stranded cDNA was repaired at the end, added a tail and connected to the sequencing adaptor; and v) PCR amplification was performed and the constructed sequencing library was used for sequencing. After the construction of the library, Agilent 2100 Bioanalyzer was used to detect the insert range of the library and ABI StepOnePlus ${ }^{\mathrm{TM}}$ real time PCR system was used to quantify the concentration of the library. After the quality inspection was qualified, Illumina hiseq sequencer (Illumina, Inc.) was used for sequencing.

Construction of siRNA. To knock down MAGEA6, three short interfering (si)RNAs were constructed (si-MAGEA6) and a 
Table I. Primers for short interfering RNA.

\begin{tabular}{ll}
\hline Primer & \multicolumn{1}{c}{ Sequence, 5'-3' } \\
\hline MAGEA6-1 forward & GCCCTCTCACTTCCTCCTT \\
MAGEA6-1 reverse & AAGGAGGAAGTGAGAGGGC \\
MAGEA6-2 forward & CCAAGGGCCCTCATTGAAA \\
MAGEA6-2 reverse & TTTCAATGAGGGCCCTTGG \\
MAGEA6-3 forward & CCTCATTGAAACCAGCTAT \\
MAGEA6-3 reverse & ATAGCTGGTTTCAATGAGG
\end{tabular}

MAGEA6, melanoma antigen gene family A.

non-targeting negative control (si-NC) (Table I), which were synthesised by Guangzhou RiboBio Co., Ltd. Eca109 cells $\left(2 \times 10^{5}\right.$ cells/well) were seeded into 6 -well plates overnight before they were transfected with the three siRNAs or si-NC (100 nM) using the FuGENE HD transfection reagent (Promega Corporation), according to the manufacturer's protocol. After $48 \mathrm{~h}$, results were detected by reverse transcription-quantitative PCR (RT-qPCR). The most effective siRNA was then selected for further experiments, where the transfected cells were named Eca109-MAGEA6-siRNA thereafter.

Growth curve. Cell Counting Kit-8 (CCK-8) (cat. no. CA1210; Beijing Solarbio Science \& Technology Co., Ltd.) was used to assess cell viability. The Eca109 cells suspension (100 $\mu \mathrm{l} /$ well) was inoculated into a 96-well plate. The culture plate was then kept in an incubator for $\sim 6 \mathrm{~h}$ at $37^{\circ} \mathrm{C}$ with $5 \% \mathrm{CO}_{2}$. Subsequently, $10 \mu \mathrm{l}$ of CCK- 8 solution was added to each well. The culture plate was then kept in an incubator for 1-4 h at $37^{\circ} \mathrm{C}$ with $5 \% \mathrm{CO}_{2}$. Absorbance in each well was measured at $450 \mathrm{~nm}$ using a microplate reader.

Wound healing assay. Eca109 cells of the experimental group and the control group were cultured in 6-well plates (Corning, Inc.) using serum-free medium (Gibco; Thermo Fisher Scientific, Inc.). The cells were scratched using the same speed and strength with a $10-\mu 1$ pipette tip, and incubated overnight at $37^{\circ} \mathrm{C}$ with $5 \% \mathrm{CO}_{2}$. The wound healing rates were observed under an optical microscope at 0 and $12 \mathrm{~h}$ (magnification, $\mathrm{x} 40$ ). Average scratch width $=$ scratch gap area/length. Cell migration rate $=(0 \mathrm{~h}$ scratch width-scratch width after culture)/0 h scratch width x100. Thus, the migration rate of cells could be determined by imaging.

Transwell assay. Transwell assays were used to assess the cell migration and invasion using Costar chambers with Transwell inserts having an $8-\mu \mathrm{m}$ pore size (Corning, Inc.). Matrigel (Invitrogen; Thermo Fisher Scientific, Inc.) was used to coat the upper chambers at $37^{\circ} \mathrm{C}$ for $30 \mathrm{~min}$, for the invasion assay but not for the migration assay. After transfection with siRNAs or siNC, Eca109 cells $\left(5 \times 10^{4}\right)$ were suspended in serum-free medium $(200 \mu \mathrm{l})$ and seeded into the upper chamber, whereas the medium present in the lower chamber was mixed with FBS $(20 \%)$. Incubation was performed for $42 \mathrm{~h}$ at $37^{\circ} \mathrm{C}$ and $5 \% \mathrm{CO}_{2}$, before cells in the upper chamber were removed using a cotton swab. Migrated or invaded cells were fixed using $4 \%$ paraformaldehyde at room temperature for $30 \mathrm{~min}$,
Table II. Primers for reverse transcription-quantitative PCR.

Primer Sequence, 5'-3'

GAPDH forward

GAPDH reverse

MAGEA6 forward

MAGEA6 reverse

MSMO1 forward

MSMO1 reverse

\section{ACCACAGTCCATGCCATCAC TCCACCACCCTGTTGCTGTA CGGTCACAAAGGCAGAAAT AGGCAGGTGGCAAAGATG AAGTGTTTCAAAGTTCTTCTCT ATAGTGCCAAGTATCTTCAATG}

MAGEA6, melanoma antigen gene family A; MSMO1, methylsterol monooxygenase 1 . and crystal violet $(0.1 \%)$ was used to stain the cells at room temperature for $20 \mathrm{~min}$ (11). Under an inverted microscope, cells were counted based on five random fields (Olympus Corporation; magnification, $\mathrm{x} 40$ ).

$R N A$ extraction and $R T-q P C R$. TRIzol ${ }^{\circledR}$ reagent (Thermo Fisher Scientific, Inc.) was used to extract total RNA from Eca109 cells according to the standard protocol. The Prime Script ${ }^{\mathrm{TM}}$ RT reagent Kit (Takara Bio, Inc.) was used to synthesise cDNA from a total of $200 \mathrm{ng}$ RNA, following which the SYBR ${ }^{\circledR}$ Green Kit (Promega Corporation) was used for amplification for qPCR as previously described (12). RT-qPCR was performed at $50^{\circ} \mathrm{C}$ for $2 \mathrm{~min}$ and $95^{\circ} \mathrm{C}$ for $2 \mathrm{~min}$, followed by 40 cycles at $95^{\circ} \mathrm{C}$ for $15 \mathrm{sec}$ and $60^{\circ} \mathrm{C}$ for $1 \mathrm{~min}$. GAPDH was used as the internal reference, and the quantitative study of primer level of MAGEA6 was normalised to that of GAPDH. The sequences of the MAGEA6 and GAPDH primers used for RT-qPCR are listed in Table II.

Western blotting. After $72 \mathrm{~h}$ of cell transfection, Eca109-MAGEA6-3.1 and control (Eca109-3.1) cells were lysed with RIPA buffer (Beyotime Institute of Biotechnology), which was used as a protein extraction reagent. The protease inhibitor PMSF (Roche Diagnostics) was also added as a supplement in the protein extraction reagent. The protein was transferred to polyvinylidene difluoride film membranes after separation of equal amounts of protein at $50 \mu \mathrm{g}$ by $12 \%$ SDS-polyacrylamide gel electrophoresis (13). BCA protein quantification was used. The membranes were blocked with QuickBlock ${ }^{\mathrm{TM}}$ Blocking Buffer for Western Blot (Beyotime Institute of Biotechnology) for $1 \mathrm{~h}$ at room temperature and subsequently incubated with rabbit anti-human MAGEA6 polyclonal antibody (1:5,000; ProteinTech Group, Inc.) for $12 \mathrm{~h}$ at room temperature. The membranes were then incubated with horseradish enzyme labelled Goat anti-rabbit IgG (1:10,000; cat. no. 2301; OriGene Technologies, Inc.) and incubated at room temperature for $1 \mathrm{~h}$ after washing three times with TBS with 20\% Tween-20. Bands were visualised using Super ECL plus (cat. no. p1050; Applygen Technologies, Inc.) on a Luminoskan chemiluminescence reader (Thermo Fisher Scientific, Inc.). GAPDH was used as the control.

Statistical analysis. Data are expressed as the mean \pm standard deviation. Each experiment was repeated three times to ensure 
that all the data were consistent. All data were calculated using GraphPad Prism v8.4.3 (GraphPad Software, Inc.). One-way ANOVA followed by Tukey's post hoc test was used to determine that the difference was statistically significant and multiple comparisons were performed using SPSS 19 software (version, 19; IBM Corp.). $\mathrm{P}<0.05$ was considered to indicate a statistically significant difference.

Bioinformatical analyses. This part is from Beijing igeneCode Biotech Co., Ltd. Responsible. After Illumina Hiseq sequencing, FastQC software (v0.11.2; Beijing igeneCode Biotech Co., Ltd.) was used to evaluate and sort the raw data into fastq format, before NGSQC software (v2.3.2) was used to filter out low-quality data. Subsequently, the default parameter HISAT software (v2.0.4) was used to compare the clean reads with high-quality to the reference genome, before the 'heatmap' function in the R software (https://www.r-project. org) was used to perform hierarchical clustering analysis and a heatmap for the sequencing data that cannot be directly aligned with the reference genome. The differential gene data obtained was screened by sequencing with thresholds of $\mathrm{P}<0.05, \log _{2}$ (fold-change) $>1.5$, and entering the selected genes into the Database for Annotation, Visualization and Integrated Discovery v6.8 (https://david.ncifcrf.gov/home.jsp) to obtain the Gene Ontology (GO) and Kyoto Encyclopaedia of Genes and Genomes (KEGG) pathway enrichment data. GraphPad Prism v8 was used to generate histograms. For analysis of the protein-protein interaction (PPI) network of methylsterol monooxygenase 1 (MSMO1) with a combined score $>0.6$, The Search Tool for the Retrieval of Interacting Gene (STRING; https://string-db.org/) was used. Construction of the PPI network was performed after downloading and importing results to the Cytoscape software [v3.5.1; https://cytoscape. org; $\mathrm{P}<0.05, \log _{2}$ (fold-change) $>1.5$ ] (14).

\section{Results}

Measurement of MAGEA6 gene expression level and cell selection. By comparing the expression of MAGEA6 in three oesophageal cancer cells and Hacat cells, it was revealed that MAGEA6 is expressed at low levels in Hacat cells but is generally expressed at higher levels in oesophageal cancer cells (Fig. 1). The expression level of MAGEA6 mRNA in the oesophageal cancer cell line Eca109 was significantly elevated compared with that in Hacat cells $(\mathrm{P}<0.01)$. MAGEA6 mRNA expression in the EC9706 oesophageal cancer cell line was significantly elevated compared with that in Hacat cells $(\mathrm{P}<0.05)$. The expression level of MAGEA6 mRNA in the KYSE150 oesophageal cancer cell line was significantly elevated compared with that in Hacat cells $(\mathrm{P}<0.01)$.

MAGEA6 overexpression promotes oesophageal cancer cell proliferation. A Eca109 cell line overexpressing MAGEA6 (Eca109-MAGEA6-3.1) and one with MAGEA6 expression knocked down (Eca109-MAGEA6-siRNA) were constructed. The effect of MAGEA6 on cell proliferation was assessed using the CCK-8 kit (Fig. 2). The results demonstrated that the overexpression of MAGEA6 promoted cell proliferation, whereas MAGEA6 knockdown had an inhibitory effect on cell proliferation in Eca109 cells in vitro.

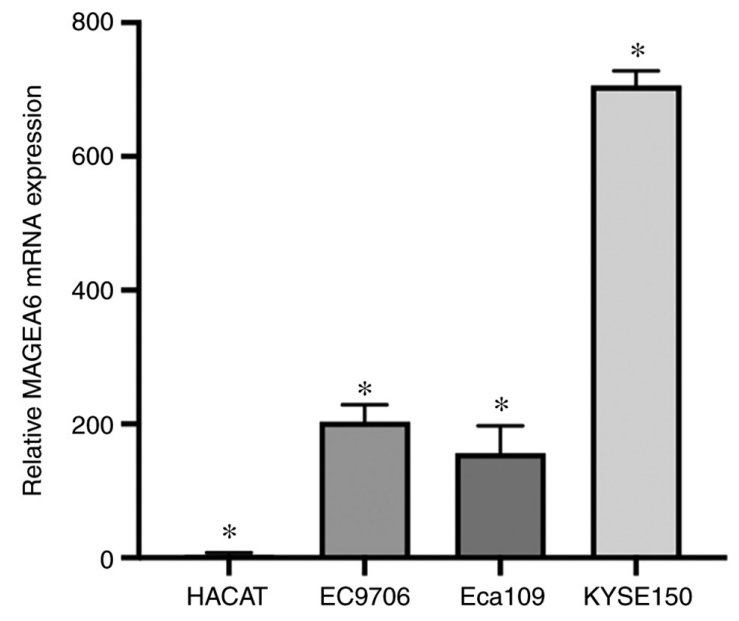

Figure 1. Expression of MAGEA6 gene detected by reverse transcription-quantitative PCR. "P<0.05 vs. control. MAGEA6, melanoma antigen gene family A.

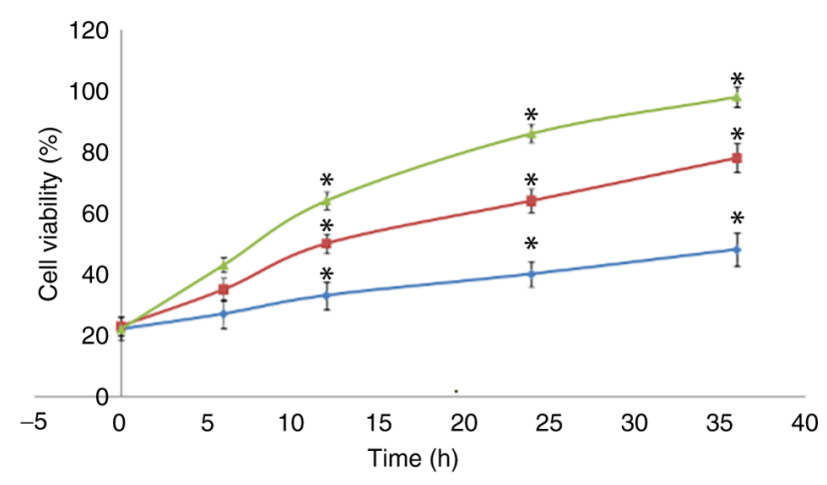

$\rightarrow$ Eca109-MAGEA6-siRNA -- Eca109-3.1 - Eca109-MAGEA6-3.1

Figure 2. Proliferation experiments were performed every $12 \mathrm{~h}$ using Cell Counting Kit-8. The proliferation of Eca109-MAGEA6-3.1, Eca109-3.1 and Eca109-MAGEA6-siRNA cells were compared. MAGEA6, melanoma antigen gene family A; si, short interfering; OD, optical density. ${ }^{*} \mathrm{P}<0.05$ vs. $0 \mathrm{~h}$

MAGEA6 increases oesophageal cancer cell migration and invasion in vitro. To explore the physiological function of MAGEA6 in oesophageal cancer and its role in the invasion of ESCC cells, Transwell assays were performed using the Eca109 cell line (Fig. 3A). The expression levels of MAGEA6 in Eca109-MAGEA6-3.1 was notably higher than that in Eca109-3.1 (Fig. 3B). As indicated in Fig. 3C, siRNA3 was the most efficient at knocking down MAGEA6 expression in Eca109 cells $(\mathrm{P}<0.05)$. Eca109-MAGEA6-3.1 cells exhibited significantly higher cell invasion rates through the Matrigel matrix compared with those by Eca109-3.1 cells $(\mathrm{P}<0.01$; Fig. 3D). By contrast, Eca109-MAGEA6-siRNA cells demonstrated significantly reduced cell invasion and invasion in the Transwell assays (Fig. 3D; $\mathrm{P}<0.05$ ). Results from wound healing assay also demonstrated that Eca109 cells overexpressing MAGEA6 migrated significantly faster compared with that in Eca109-3.1 cells $(\mathrm{P}<0.05$; Fig. 4).

Cluster analysis of MAGEA6 differentially expressed genes. According to the two groups of stable cell lines, with each having three replicates, hierarchical cluster analysis was 


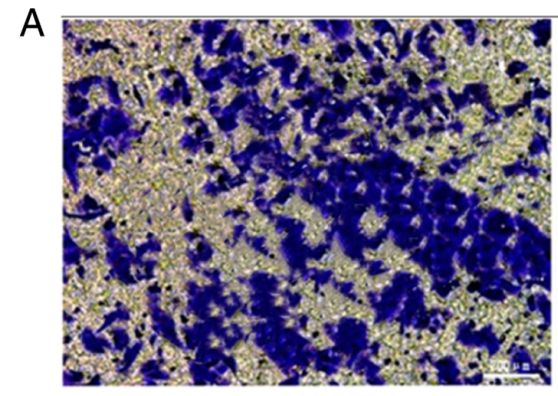

Eca109-3.1

B

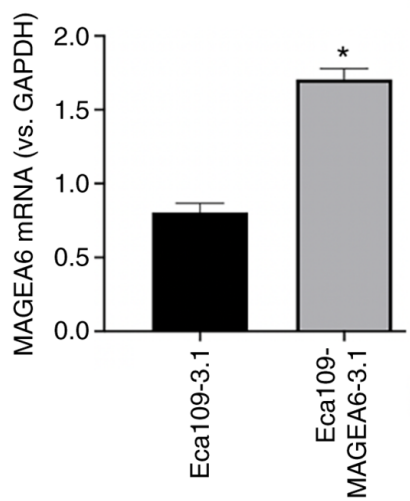

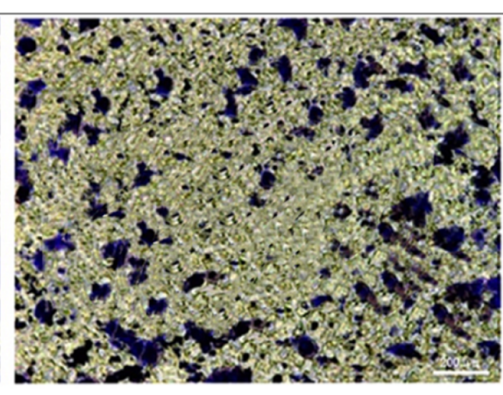

Eca109-MAGEA6-siRNA

C

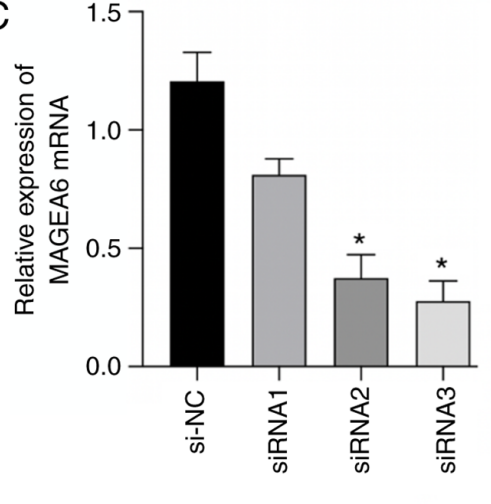

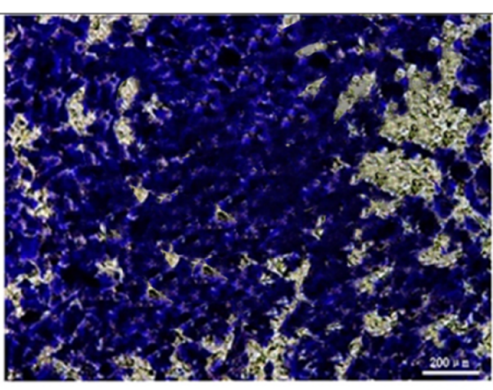

Eca109-MAGEA6-3.1

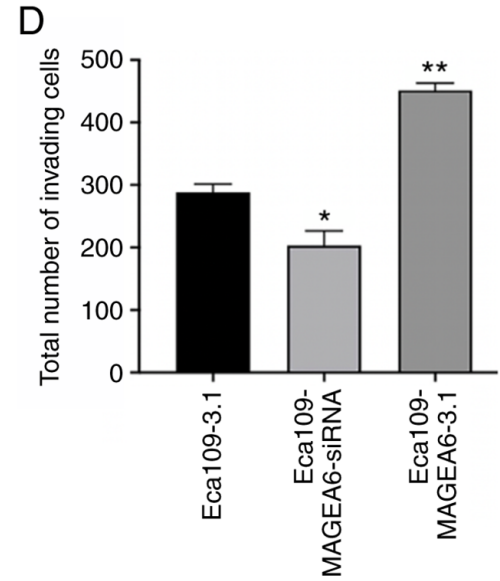

Figure 3. Effects of MAGEA6 on the invasion ability of Eca109 cells. (A) Invasion assay images of Eca109-MAGEA6-siRNA, Eca109-MAGEA6-3.1 and Eca109-3.1 cells, which were captured under x10 magnification after $42 \mathrm{~h}$. (B) Reverse transcription-quantitative PCR verification of MAGEA6 overexpression in Eca109 cells ("P<0.05 vs. Eca109-3.1). (C) Compared with the si-NC, siRNA3 was found to be the most effective at knocking down MAGEA6 expression out of the three designed siRNAs ("P<0.01 vs. Eca109-3.1 and si-NC). (D) Quantification of cell invasiveness in Eca109-MAGEA6-siRNA cells compared with Eca109-3.1 and Eca109-MAGEA6-3.1 cells ("P<0.05 and ${ }^{* *} \mathrm{P}<0.01$ vs. Eca109-3.1). MAGEA6, melanoma antigen gene family A; si, short interfering; NC, negative control.
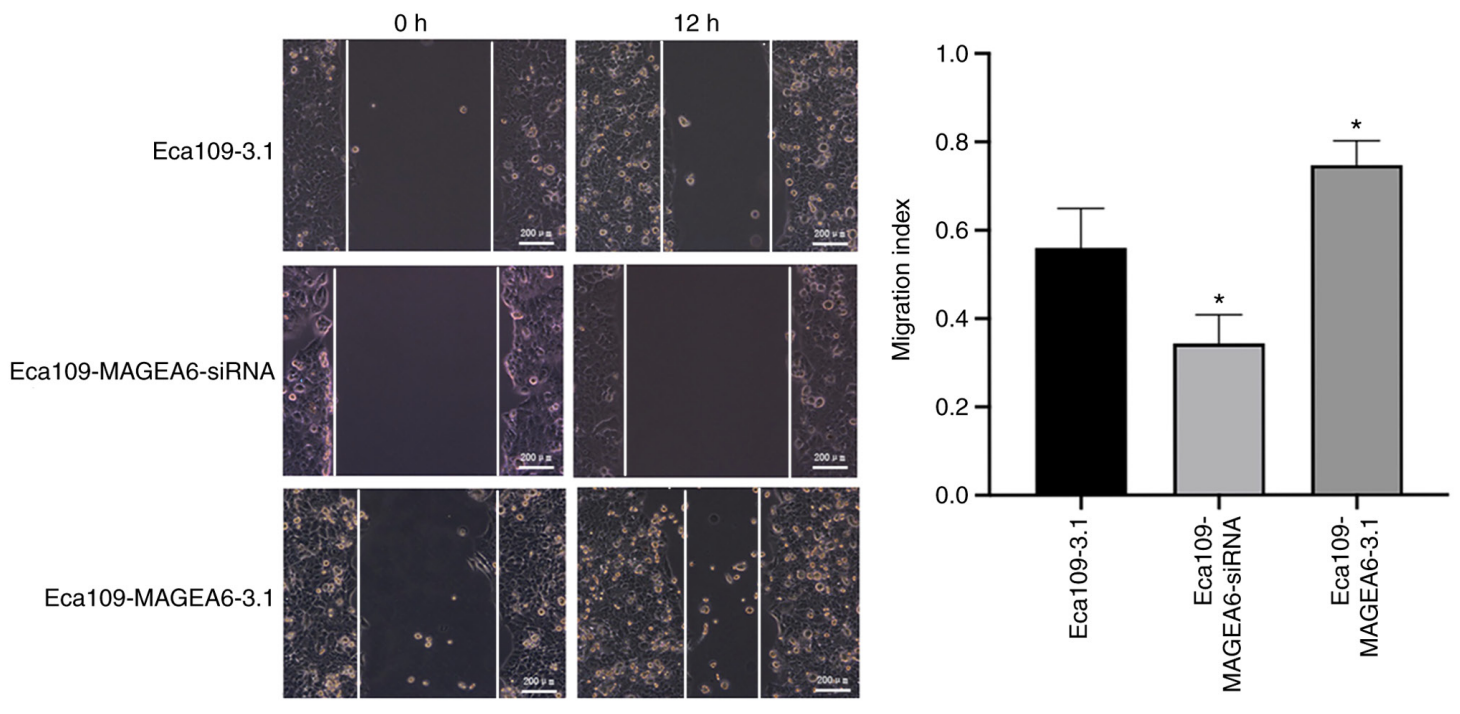

Figure 4. Wound healing assay results in Eca109-3.1, Eca109-MAGEA6-siRNA and Eca109-MAGEA6-3.1 cell lines. Images of the wounds were captured at 0 and $12 \mathrm{~h}$ post-scratch (magnification, $\mathrm{x} 10$ ) and cell migration was calculated at the two time points in the different cell lines. " $\mathrm{P}<0.05$ vs. Eca109-3.1. MAGEA6, melanoma antigen gene family A; si, short interfering.

performed through transcriptome sequencing analysis. Different coloured areas represent different cluster grouping information. Within each experimental repeat of the same group, gene expression patterns were similar, which may have similar functions or participate in the same biological processes. Fig. 5 demonstrates the differences between the two groups of cells. Compared with the control, GDF15, ATF3, GADD45A and MSMO1 were highly upregulated, whereas TFRC, IGFBP1, PAPPA2, HAL and CHL1 were significantly downregulated. 


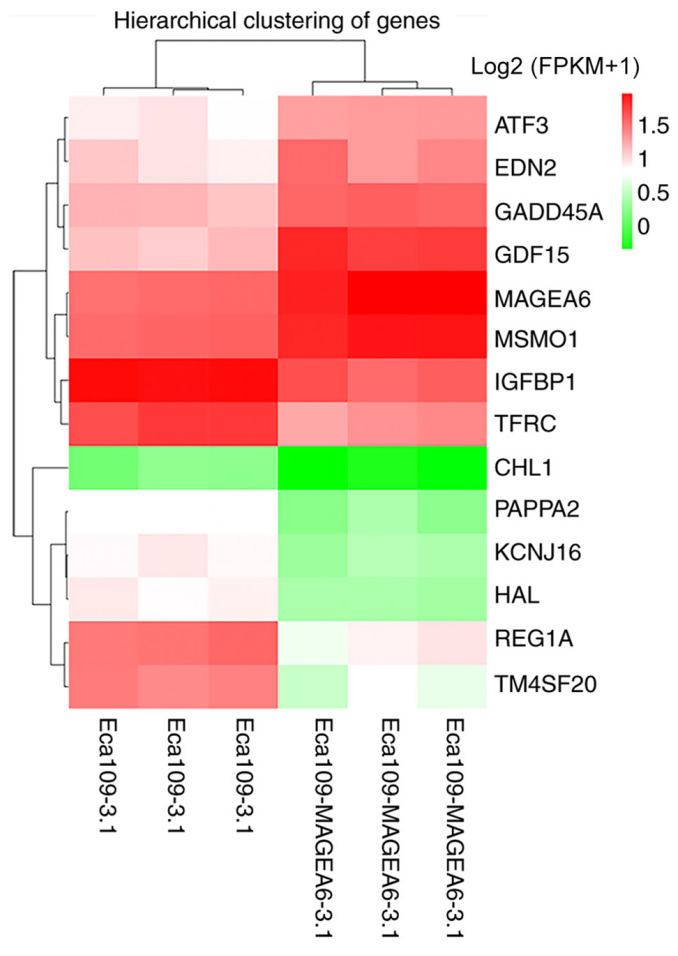

Figure 5. Cluster heat map of differentially expressed genes after MAGEA6 overexpression. Abscissa represents the sample name and sample clustering results, whereas the ordinate represents the differentially expressed genes and gene clustering results. Different columns represent the different Eca109-3.1 and Eca109-MAGEA6-3.1 samples, whilst different rows represent the expression of the different genes. The color represents the gene expression level $\log _{2}(\mathrm{FPKM}+1)$ in the sample (R software heatmap). Red represents a high degree of enrichment and green represents a low degree of enrichment. MAGEA6, melanoma antigen gene family A; ATF3, activating transcription factor 3; EDN2, endothelin 2; GADD45A, growth arrest and DNA damage inducible alpha; GDF15, growth differentiation factor 15; MSMO1, methylsterol monooxygenase 1; IGFBP1, insulin like growth factor binding protein 1; TFRC, transferrin receptor; CHL1, cell adhesion molecule L1 like; PAPPA2, pappalysin 2; KCNJ16, potassium inwardly rectifying channel subfamily $\mathrm{J}$ member 16 ; HAL, histidine ammonia-lyase; REG1A, regenerating family member 1 alpha; TM4SF20, transmembrane 4 L six family member 20 .

Analysis of differentially expressed genes after MAGEA6 overexpression. A Minus-vs.-Add diagram can be used to visually examine the overall distribution of gene expression levels and differential multiples of two experimental samples for comparison (15). In Fig. 6, upregulated genes are represented by red dots, whereas downregulated genes are represented by blue dots, and non-differentially expressed genes are represented by black dots. Compared with the control, GDF15, ATF3, GADD45A and MSMO1 were highly upregulated, whereas TFRC, IGFBP1, PAPPA2, HAL and CHL1 were significantly downregulated.

Number of differentially expressed genes after MAGEA6 overexpression in different alignment schemes and protein level verification. Sequence analysis of the target genes and proteins in Cytoscape revealed a differential gene interaction network after MAGEA6 overexpression (Fig. 7). By sequencing the Eca109-3.1 and Eca109-MAGEA6-3.1 cells, 14 genes were revealed to be closely associated with MAGEA6 overexpression. Yellow indicates upregulation and blue indicates downregulation. GDF15, ATF3, GADD45A and

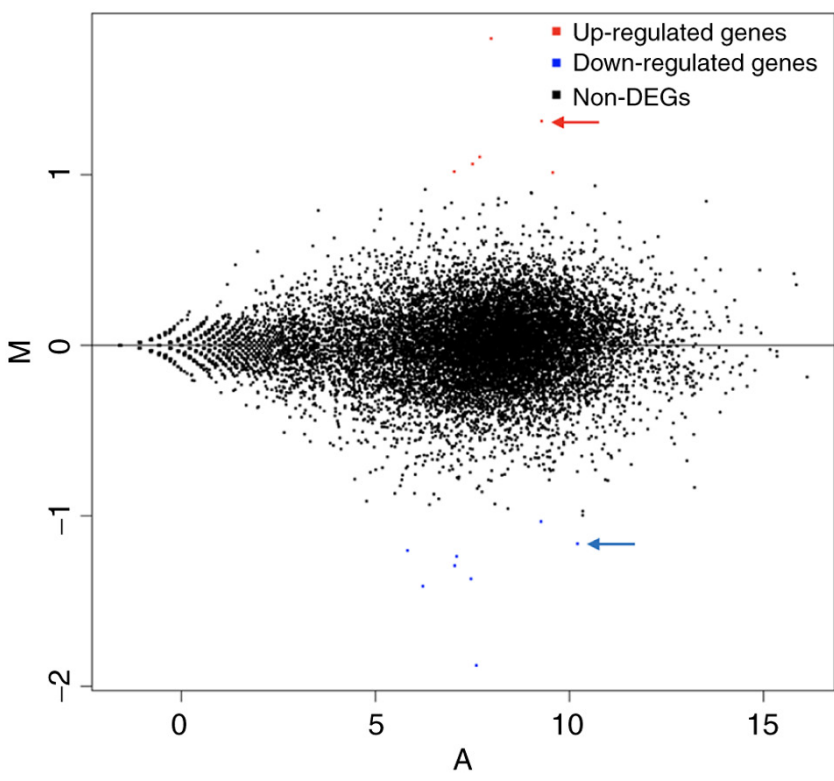

Figure 6. MA map (produced by R software DEseq2) of differentially expressed genes after MAGEA6 overexpression. Each dot in the MA map represents a gene. Abscissa represents the $\log _{2}$ (FPKM) or the A value, which is the logarithmic value of the mean expression quantity in Eca109-MAGEA6-3.1 and Eca109-3.1 groups. Ordinate is $\mathrm{M}$ value: $\log _{2}(\mathrm{Fc})$, which is the logarithmic value of the multiple of gene expression difference between the two samples, used to measure the difference in gene expression. In the figure, red dots represent upregulated genes, blue dots represent downregulated genes and black dots represent not differentially expressed genes. Fc, fold-change; $\mathrm{A}, \log 2(\mathrm{FPKM})$ value; $\mathrm{B}, \log 2(\mathrm{Fc}) ;$ MAGEA6, melanoma antigen gene family A; DEGs, differentially expressed genes; MA, Minus-vs.-Add.

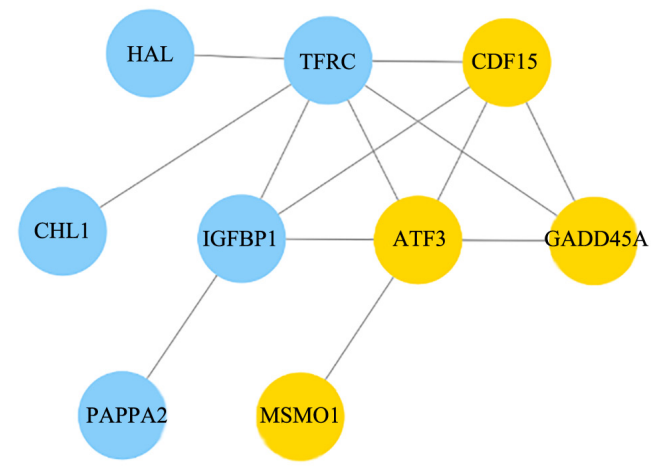

Figure 7. Protein interaction network diagram of differentially expressed genes after MAGEA6 overexpression, analyzed using Cytoscape. Each node in the figure represents a differentially expressed gene and its corresponding protein. Yellow dots represent a gene that was upregulated whereas blue dots represent a gene that was downregulated. MAGEA6, melanoma antigen gene family A; HAL, histidine ammonia-lyase; TFRC, transferrin receptor; GDF15, growth differentiation factor 15; CHL1, cell adhesion molecule L1 like; IGFBP1, insulin like growth factor binding protein 1; ATF3, activating transcription factor 3; GADD45A, growth arrest and DNA damage inducible alpha; PAPPA2, pappalysin 2; MSMO1, methylsterol monooxygenase 1 .

MSMO1 were highly upregulated, whereas TFRC, IGFBPI, PAPPA2, HAL and CHL1 were significantly downregulated. According to the functions of these genes, GDF15, GADD45A, MSMO1,EDN2, REG1A and PAPPA2 are found to be closely associated with the occurrence of cancer, these genes have great research value in tumor (Table III). The function of 
Table III. Verification and function the expression levels of differentially expressed proteins after MAGEA6 overexpression.

\begin{tabular}{|c|c|c|c|}
\hline Gene & Gene regulation & Fold-change, $\log _{2}$ & Function \\
\hline GDF15 & Up & 1.798961725 & $\begin{array}{l}\text { After cell injury, it participates in the process of cell stress response, } \\
\text { where increases in its level is associated with inflammation and acute } \\
\text { injury (14). }\end{array}$ \\
\hline ATF3 & Up & 1.062712819 & $\begin{array}{l}\text { Involved in cell cycle progression and stimulation of invasive and } \\
\text { metastatic genes }(30) \text {. }\end{array}$ \\
\hline GADD45A & Up & 1.104190772 & $\begin{array}{l}\text { DNA damaging agent treatment increases and promotes oesophageal } \\
\text { squamous cell carcinoma cell proliferation (31). }\end{array}$ \\
\hline MSMO1 & Up & 1.012811618 & $\begin{array}{l}\text { It serves an important role in the biosynthesis of lipids and also plays } \\
\text { a regulatory role in cell proliferation and immune regulation (32). }\end{array}$ \\
\hline EDN2 & Up & 1.018092856 & $\begin{array}{l}\text { EDN are produced by ovarian follicles and are involved in the } \\
\text { regulation of steroidogenesis of GC of several mammalian species } \\
\text { including humans, cattle, pigs and rats (33). }\end{array}$ \\
\hline MAGEA6 & Up & 1.314680031 & $\begin{array}{l}\text { Elevated expression in cancer cells but not in normal cells. It is a } \\
\text { tumor marker and promotes the migration and invasion of cancer } \\
\text { cells, such as human glioma cells }(6) \text {. }\end{array}$ \\
\hline REG1A & Down & -1.413208462 & $\begin{array}{l}\text { It is associated with islet cell regeneration and diabetogenesis and may } \\
\text { be involved in pancreatic lithogenesis (34). }\end{array}$ \\
\hline TM4SF20 & Down & -1.877859733 & $\begin{array}{l}\text { Deletion mutations in this gene are associated with specific language } \\
\text { disorders, such as language delay (35). }\end{array}$ \\
\hline KCNJ16 & Down & -1.23791537 & May serve a role in liquid and pH balance adjustment (36). \\
\hline TFRC & Down & -1.163899233 & $\begin{array}{l}\text { This gene encodes a cell surface receptor, which is required for the } \\
\text { uptake of iron through receptor-mediated endocytosis (37). }\end{array}$ \\
\hline IGFBP1 & Down & -1.033847315 & $\begin{array}{l}\text { It serves a major role in cell migration and metabolism. When used in } \\
\text { low doses, it stimulates cell proliferation (38). }\end{array}$ \\
\hline PAPPA2 & Down & -1.369985674 & $\begin{array}{l}\text { Inhibit the migration, invasion and tube formation of extracellular } \\
\text { trophoblasts (39). }\end{array}$ \\
\hline HAL & Down & -1.292750813 & $\begin{array}{l}\text { One of the main reasons for the increased histidine and histamine and } \\
\text { decreased urocanic acid in body fluids(a substance found in body } \\
\text { fluids) (40). }\end{array}$ \\
\hline CHL1 & Down & -1.203237487 & $\begin{array}{l}\text { It is a neural recognition molecule that may participate in signal } \\
\text { transduction pathways }(41) \text {. }\end{array}$ \\
\hline
\end{tabular}

MSMO1, methylsterol monooxygenase 1; GDF15, growth differentiation factor 15; ATF3, activating transcription factor 3; GADD45A, growth arrest and DNA damage inducible alpha; EDN2, endothelin 2; MAGEA6, melanoma antigen gene family A; REG1A, regenerating family member 1 alpha; TM4SF20, transmembrane $4 \mathrm{~L}$ six family member 20; KCNJ16, potassium inwardly rectifying channel subfamily J member 16; TFRC, transferrin receptor; IGFBP1, insulin like growth factor binding protein 1; PAPPA2, pappalysin 2; HAL, histidine ammonia-lyase; CHL1, cell adhesion molecule L1 like.

some of these genes can be found in NCBI (https://www.ncbi. nlm.nih.gov).

GO function classification of differentially expressed genes after MAGEA6 overexpression. According to analyses of cellular component, molecular function and biological processes using the threshold of $\mathrm{P}<0.05$ and $\log _{2}$ (fold change) $>1.5$, it was observed that the proteins encoded by these enriched genes are mainly concentrated in the space outside the cell (the red one) and the 'endoplasmic reticulum'. The main molecular function was determined to be 'RNA polymerase II core promoter proximal regions sequence-specific DNA binding' and 'serine-type endopeptidase activity'. The main biological processes involved were identified as the 'negative regulation of transcription from
RNA polymerase II promoter', 'cell adhesion' and 'cholesterol biosynthesis' (Fig. 8). This result suggests that the overexpression of MAGEA6 can induce a significant impact on gene transcription.

Pathway function analysis of MAGEA6 differentially expressed genes. From the analysis of KEGG pathways using the threshold of $\mathrm{P}<0.05$ and $\log _{2}$ (fold-change) $>1.5$, it was observed that the pathways of these differentially expressed genes were mainly in the 'complement and coagulation cascade', 'biosynthesis of antibiotics' pathway and the 'cGMP-PKG signalling pathway' (Fig. 9). This indicates that MAGEA6 is closely associated with the complement cascade in the blood. 


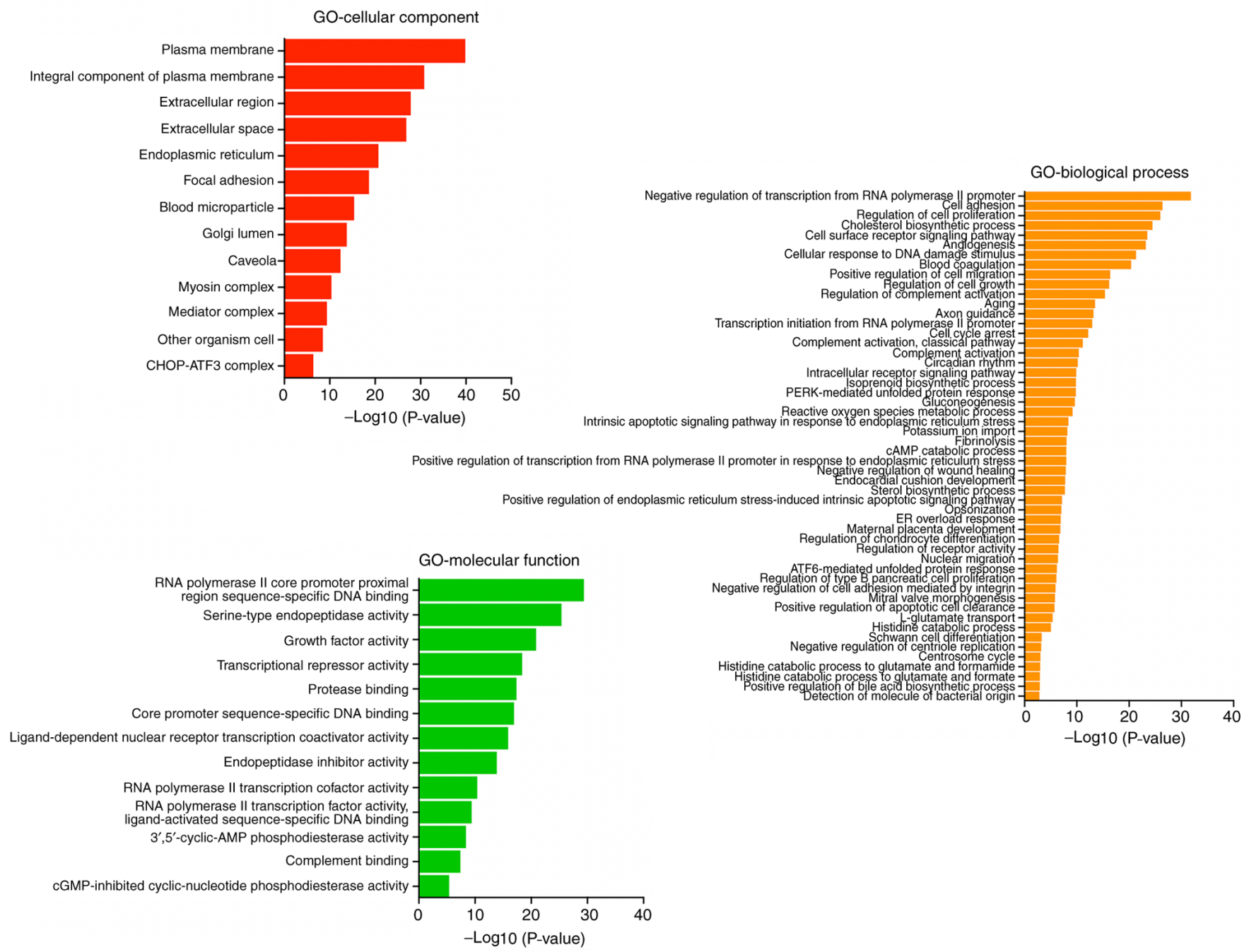

Figure 8. GO function classification chart of the differentially expressed genes after MAGEA6 overexpression. Functional GO analysis obtained from the three aspects of cellular component, biological process and molecular function is presented in the figure. The $\mathrm{x}$-axis represents the - $\log _{10}(\mathrm{P}-\mathrm{value})$, whilst the $\mathrm{y}$-axis represents a classification and each row is a subclass. MAGEA6, melanoma antigen gene family A; GO, Gene Ontology; PERK, (PKR)-like endoplasmic reticulum kinase; ER, endoplasmic reticulum; ATF, activating transcription factor; CHOP, C/EBP homologous protein.

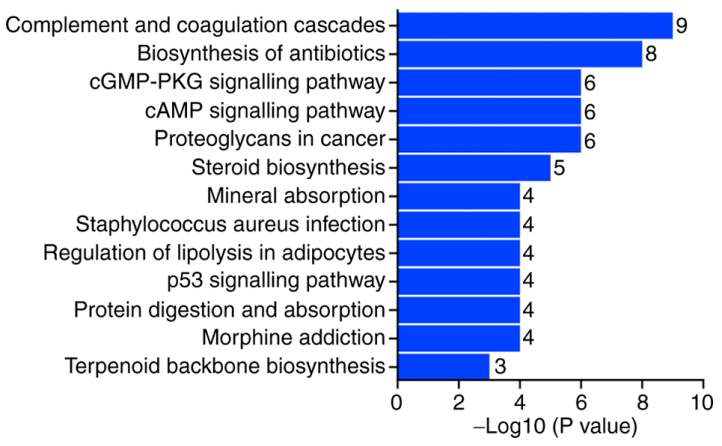

Figure 9. Kyoto Encyclopaedia of Genes and Genomes pathway function classification map of the differentially expressed genes after MAGEA6 overexpression. The $\mathrm{x}$-axis represents the $-\log _{10}(\mathrm{P}$-value $)$, whilst the $\mathrm{y}$-axis represents a classification and each row is a subclass. MAGEA6, melanoma antigen gene family A; PKG, protein kinase G.

Identification of core genes through screening of differentially expressed genes after MAGEA6 overexpression. A total of 197 differentially expressed genes were screened through the differential gene analysis report obtained from the aforementioned sequencing. These genes were analysed using the STRING website to obtain a form containing information about the corresponding interactions. This form was then applied to Cytoscape to obtain a protein interaction map. HMGCR, SQLE, FDFT1, HSD17B7, IDI1, INSIG1, DHCR7, HMGCS1, MSMO1, IRS1, DDTI3, GADD45A and HIST2H2BE were determined to be the core genes. The interaction relationship within the MSMO1 cluster of proteins can be seen from the map in Fig. 10. The larger the circle, the darker the color and the thicker the line, the more central and important the gene. Through interaction analysis, MSMO1 was found to be a core protein surrounded by multiple related pathway proteins.

Regulation of MSMO1 expression downstrea of MAGEA6 overexpression. The results of a previous screen demonstrated that MSMO1 is both a differential protein and a core protein, which may be closely associated with MAGEA6. The expression of MSMO1 increased with the increase of MAGEA6 expression (Fig. 11A). Western blotting results demonstrated that the MSMO1 expression levels were significantly higher 

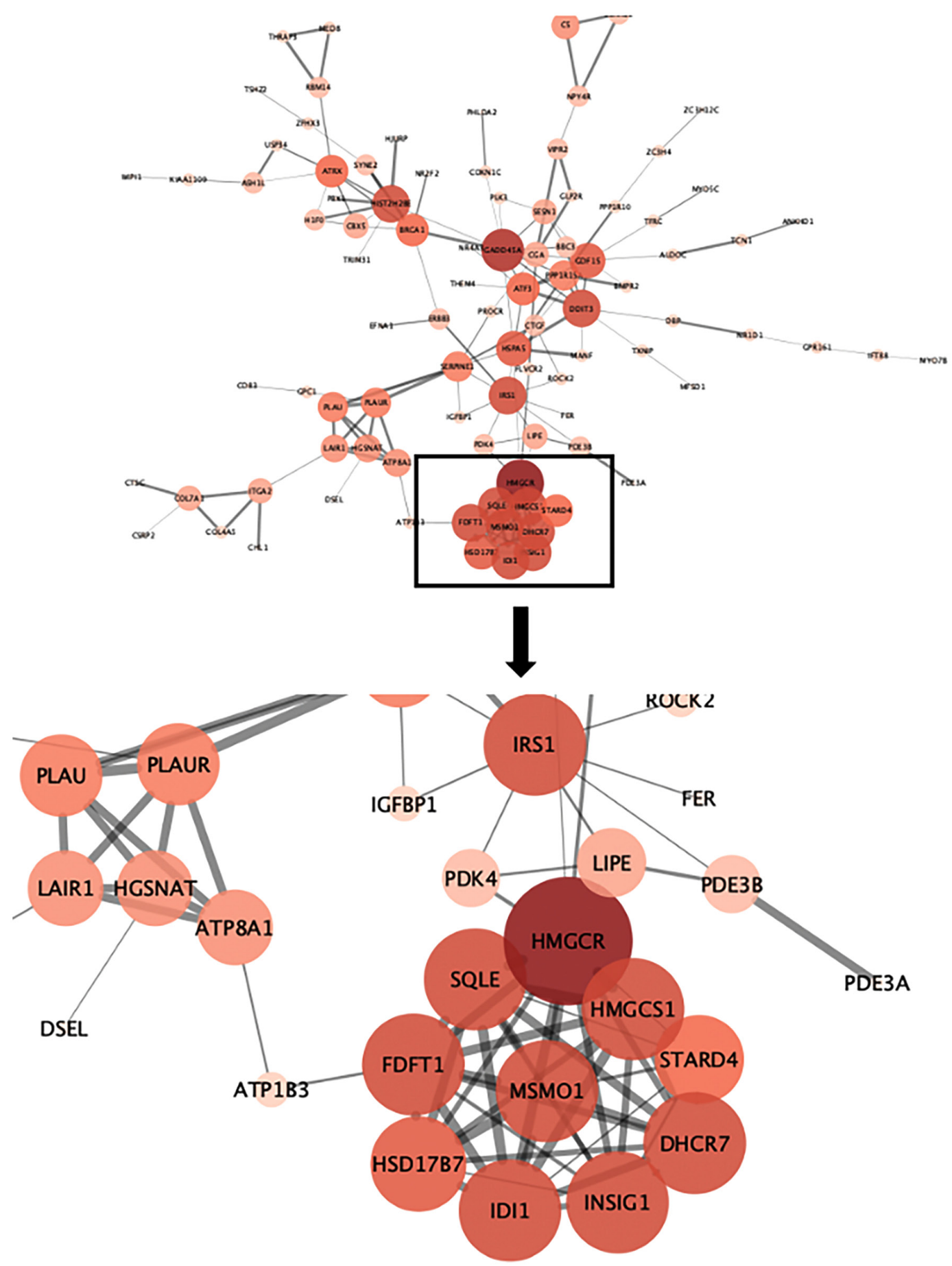

Figure 10. Protein interaction diagram of MSMO1 produced using Cytoscape. The darker the color, the more core, the larger the circle, the more core, the thicker the line, the stronger the connection and the more core. MSMO1 is an important core gene. MSMO1, methylsterol monooxygenase 1.

in Eca109-MAGEA6-3.1 cells compared with those in the Eca109-3.1 cells, which was consistent with the sequencing results (Fig. 11B and C).

\section{Discussion}

In 1991, Van Der Bruggen et al isolated the first melanoma-associated antigen (MAGE) gene from melanoma cells and named it MAGEAl, which is a type of testicular tumour antigen gene. It is expressed in tumor tissue and normal testicular cells, but not in other normal cells (16).
Subsequently, members of the MAGE family discovered were named MAGEA, B, C, D, E, F, G, H and L2, Necidin, MAGE-I and $\mathrm{J}$ (17). In addition, the tumour-associated antigen encoded by the MAGE gene can form a complex with specific human leukocyte antigen molecules that can be recognised and killed by specific cytotoxic $\mathrm{T}$ lymphocytes (18).

The $M A G E$ gene family can be categorised as either group I or II. There have been a number of studies on members of group I, including the sub-families MAGE A, B and C $(15,18)$. Although they are expressed in different types of tumour tissues, they are not expressed in normal tissues except in 

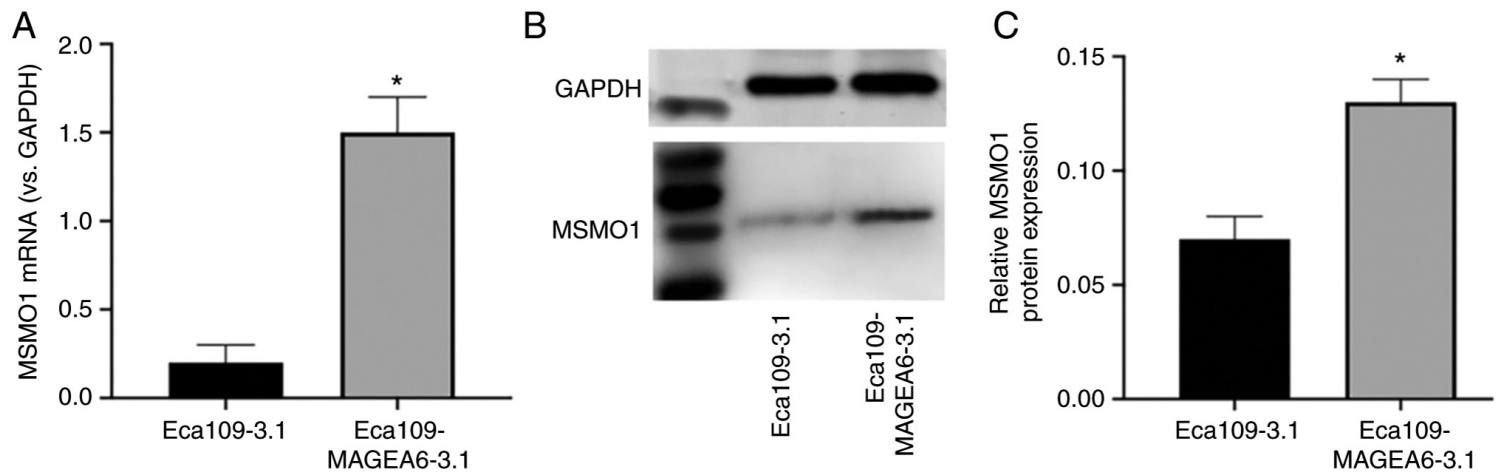

Figure 11. (A) Reverse transcription-quantitative PCR analysis of MSMO1 expression in Eca109-3.1 and Eca109-MAGEA6-3.1 cells. (B) Western blotting of MSMO1 in Eca109-3.1 and Eca109-MAGEA6-3.1 cells, (C) which was quantified. "P<0.05 vs. Eca109-3.1. MSMO1, methylsterol monooxygenase 1; MAGEA6, melanoma antigen gene family A.

testicular germ cells and placenta (15). Therefore, they are considered to be tumour-specific antigens. Previous studies have shown that the expression of MAGE is closely associated with the degree of tumour differentiation, where its expression rate increases as the degree of differentiation decreases $(15,19)$. Therefore, the level of MAGE gene expression has reliable prognostic values for a number of malignant tumours, such as stomach cancer and melanoma (19). The MAGEA gene is an important member of the MAGE-I group. Because it can encode tumour-specific antigen polypeptides, studies have reported that MAGEA family members are important target molecules for tumour immunotherapy $(19,20)$. The MAGEA gene subfamily has 15 members, which are all located on Xq28 $(19,20)$. The MAGEAl gene is $\sim 45 \mathrm{~kb}$ in length, has three exons and encodes a protein of $\sim 309-319$ amino acid residues, whereas MAGEA5, A7, A13, A14 and A15 are pseudogenes with no transcriptional products (20).

To the best of our knowledge, MAGEA3 is the most widely studied protein in the MAGEA family, which shows almost no expression in normal tissues but is expressed in different types of malignant tissues $(20,21)$. The mechanism of its action in tumour tissues is not yet fully understood. Studies have previously confirmed that MAGEA3 is highly expressed in a variety of epithelial and hematopoietic malignancies and malignant tumours derived from mesenchymal tissues $(20,21)$. Previous studies have also shown that the expression of MAGEA3 is associated with the metastasis, invasion, prognosis and recurrence of malignant tumours, suggesting that it can be used as an indicator for the diagnosis and prognosis of patients with tumours (20-22). In addition, MAGEA3 has been shown to bind KAP1 and p53, thereby inhibiting the activity of p53 and ultimately promoting the activation of melanoma cells $(21,22)$. Atanackovic et al (23) revealed that silencing the expression of $M A G E A 3$ can induce the apoptosis of malignant tumour cells, such as lung cancer, confirmed that it is not involved in the regulation of proliferation and adhesion in multiple myeloma cells, but that it can promote multiple myeloma cell proliferation (23).

Limited studies suggest that MAGEA6 may participate in the AMPK signalling pathway to inhibit the maintenance and self-renewal of liver cells, and that it mediates the survival of human glioma cells by targeting AMPKa1 (24). According to the results from the present study, although they share $\sim 98 \%$ homology, MAGEA3 and MAGEA6 have significant differences in terms of functions and pathways $(24,25)$. A preliminary study using clinical samples revealed that MAGEA6 expression is closely associated with the occurrence of oesophageal cancer (25). The present study was conducted to provide an in-depth analysis of the role of MAGEA6, which revealed that it affected cell proliferation, invasion and migration. To analyse the possible associated signalling pathways and function of MAGEA6, transcriptome sequencing and bioinformatics analysis were performed after MAGEA6 overexpression. This analysis found 14 genes with significant differences after MAGEA6 overexpression. The analysis revealed further that the majority of these 14 genes are closely associated with cell migration and proliferation, which is different from the signalling pathway in which MAGEA6 participates in human glioma cells. Contrary to a previous report, MAGEA6 is involved in other new signalling pathways, MAGEA6 and MSMO1 are mutually regulated signalling pathways (6).

After modulating the expression level of MAGEA6, it was revealed that it mainly affects the "negative regulation of transcription from RNA polymerase II promoter', 'cell adhesion' and the 'cholesterol biosynthetic pathway'. KEGG pathway analysis demonstrated that the differentially expressed genes were mainly involved in the 'complement and coagulation cascades' reaction, 'biosynthesis of antibiotics' pathway, 'cGMP-PKG signalling pathway', cAMP pathway and steroid biosynthesis pathway. To explore the role of core genes in the process of MAGEA6 function, all possible associated differential genes were analysed using Cytoscape (26). A total of 13 core regulatory genes, including MSMOI, IRS1, DDTI3 and $G A D D 45 A$, were identified. These results suggest that these genes play a key role in the function of MAGEA6.

Among these 13 core regulatory genes, MSMOI was one of 14 genes exhibiting a significant difference. It was therefore hypothesised that it serves a notable role in the function of MAGEA6. It was first verified to reveal that MAGEA6 had a significant positive regulatory relationship with MSMO1. With the increase of MAGEA6, MSMO1 gene was also significantly increased, and the migration, invasion and proliferation were significantly improved, suggesting that MAGEA6 functions by increasing the expression level of MSMO1. MSMO1 serves an important role in lipid biosynthesis by regulating human energy metabolism, obesity and 


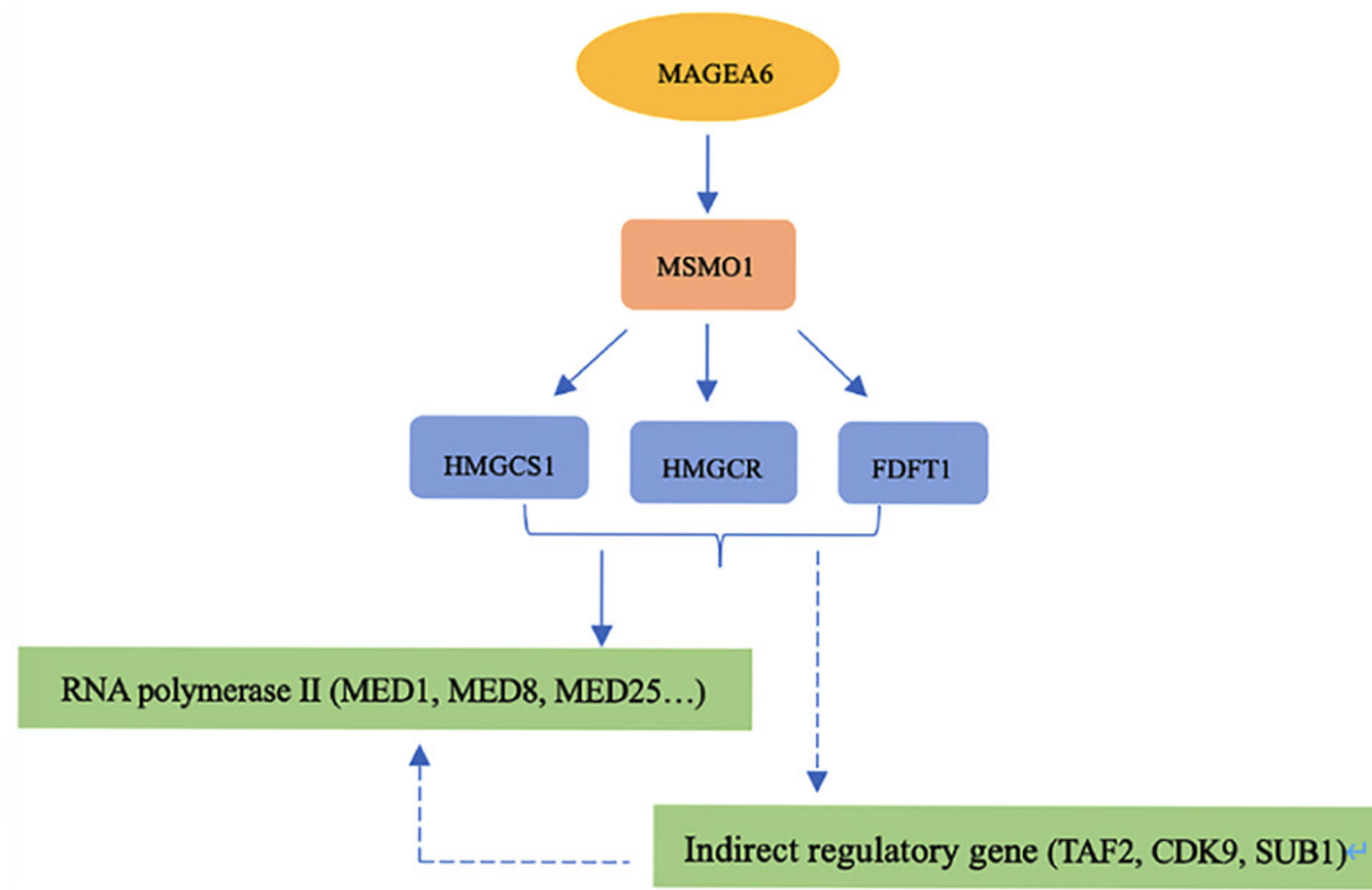

Figure 12. MSMO1 pathway prediction diagram produced using STRING. MAGEA6 may affect cellular transcription by regulating MSMO1 to affect RNA polymerase II activity. MSMO1, methylsterol monooxygenase 1; MAGEA6, melanoma antigen gene family A; HMGCS1, HMG-CoA synthase 1; HMGCR, 3-hydroxy-3-methylglutaryl-coenzyme A reductase; FDFT1, farnesyl-diphosphate farnesyltransferase 1; MED, mediator of RNA polymerase II transcription; TAF2, transcription initiation factor TFIID subunit 2; CDK9, cyclin-dependent kinase 9; SUB1, activated RNA polymerase II transcriptional coactivator p15.

dyslipidaemia, which in turn plays a regulatory role in cell proliferation and immune regulation $(27,28)$. At present, research on MSMO1 has mainly focused on cholesterol synthesis and fat metabolism (29). This may represent a new signalling pathway involved in regulation of the function of MAGEA6. It is hypothesized that MAGEA6 may indirectly affect RNA polymerase II by influencing multiple genes by regulating genes such as MSMO1, which provides a novel direction to reveal the function of and signal pathways associated with MAGEA6 with ESCC (Fig. 12).

In conclusion, MAGEA6 can enhance the migratory ability of ESCC cells. Invasion experiments on three kinds of cells, namely Eca109-MAGEA6-3.1, Eca109-3.1 and Eca109-MAGEA6-siRNA revealed that the MAGEA6 overexpression increased the invasive potential of Eca109 cells. MAGEA6 overexpression in cells affected both cell migration and invasion. The migration rate of cells with high MAGEA6 expression was significantly increased, while that of cells with low MAGEA6 expression was significantly reduced. After obtaining the differential genes closely associated with the upregulation of MAGEA6 expression, transcriptome analysis identified a series of core genes closely associated with the regulation of MAGEA6 expression, especially MSMO1. This suggests that MAGEA6 positively regulates MSMO1 expression, where it may serve an important role in ESCC cells.
MAGEA6 could therefore be a multifunctional protein that can affect cell metabolism and proliferation.

\section{Acknowledgements}

The authors would like to thank Mr. Li Jintao (Beijing Key Laboratory of Environmental and Viral Oncology, College of Life Science and Bio-Engineering, Beijing University of Technology, Beijing, P.R. China) for providing bioinformatics correlation analysis software (FastQC Software; V0.11.2) to complete the analysis of the experimental results.

\section{Funding}

Funding was provided by The Scientific Research Project of Beijing Educational Committee (grant no. KM201910005004), The Beijing Natural Science Foundation (grant no. 5162003) and The Beijing University of Technology Foundation (grant no. 015000514314004).

\section{Availability of data and materials}

The high-throughput sequencing datasets generated and/or analysed during the current study are available in the NCBI 
database (accession no. PRJNA693685; https://www.ncbi.nlm nih.gov).

\section{Authors' contributions}

ML wrote the manuscript and designed the RT-qPCR primers. YW helped perform the RT-qPCR experiment. CL helped perform the western blotting. ML, MW and YY designed the gene sequencing, and analysed the sequencing data. JL completed the bioinformatics analysis, literature retrieval and statistical analysis. ML and JL confirm the authenticity of all the raw data. MG revised the manuscript, and participated in the analysis of bioinformatics data, as well as the experimental conception. All authors have read and approved the final manuscript.

\section{Ethics approval and consent to participate}

Not applicable.

\section{Patient consent for publication}

Not applicable.

\section{Competing interests}

The authors declare that they have no competing interests.

\section{References}

1. Montelli A, Dowdeswell JA, Ottesen D and Johansen SE: 3D seismic evidence of buried iceberg ploughmarks from the mid-Norwegian continental margin reveals largely persistent North Atlantic current through the quaternary. Mar Geol 399: $66-83,2018$

2. Kirkin AF, Dzhandzhugazyan KN and Zeuthen J: Cancer/testis antigens: Structural and immunobiological properties. Cancer Invest 20: 222-236, 2002.

3. Kumar N, Sood D, Gupta A, Jha NK, Jain P and Chandra R: Cytotoxic T-lymphocyte elicited therapeutic vaccine candidate targeting cancer against MAGE-A11 carcinogenic protein Biosci Rep 40: BSR20202349, 2020.

4. Kuldkepp A, Karakai M, Toomsoo E, Reinsalu O and Kurg R: Cancer-testis antigens MAGEA proteins are incorporated into extracellular vesicles released by cells. Oncotarget 10 : 3694-3708, 2019.

5. Gao X, Li Q, Chen G, He H and Ma Y: MAGEA3 promotes proliferation and suppresses apoptosis in cervical cancer cells by inhibiting the KAP1/p53 signaling pathway. Am J Transl Res 12: 3596-3612, 2020.

6. Pan SJ, Ren J, Jiang H, Liu W, Hu LY, Pan YX, Sun B, Sun QF and Bian LG: MAGEA6 promotes human glioma cell survival via targeting AMPK $\alpha 1$. Cancer Lett 412: 21-29, 2018.

7. Pineda CT and Potts PR: Oncogenic MAGEA-TRIM28 ubiquitin ligase downregulates autophagy by ubiquitinating and degrading AMPK in cancer. Autophagy 11: 844-846, 2015.

8. Shukla SA, Bachireddy P, Schilling B, Galonska C, Zhan Q, Bango C, Langer R, Lee PC, Gusenleitner D, Keskin DB, et al: Cancer-germline antigen expression discriminates clinical outcome to CTLA-4 blockade. Cell 173: 624-633.e8, 2018.

9. Wong PP, Yeoh CC, Ahmad AS, Chelala C, Gillett C, Speirs V, Jones JL and Hurst HC: Identification of MAGEA antigens as causal players in the development of tamoxifen-resistant breast cancer. Oncogene 33: 4579-4588, 2014.

10. Schooten E, Di Maggio A, van Bergen En Henegouwen PMP and Kijanka MM: MAGE-A antigens as targets for cancer immunotherapy. Cancer Treat Rev 67: 54-62, 2018.

11. Morgan RA, Chinnasamy N, Abate-Daga D, Gros A, Robbins PF, Zheng Z, Dudley ME,Feldman SA, Yang JC, Sherry RM, et al: Cancer regression and neurological toxicity following anti-MAGE-A3 TCR gene therapy. J Immunother 36: 133-151, 2013.
12. Hao J, Li S, Li J, Jiang Z, Ghaffar M, Wang M, Jia R, Chen S, Wang Y and Zeng Y: Investigation into the expression levels of MAGEA6 in esophageal squamous cell carcinoma and esophageal adenocarcinoma tissues. Exp Ther Med 18: 1816-1822, 2019.

13. Fon Tacer K, Montoya MC, Oatley MJ, Lord T, Oatley JM, Klein J, Ravichandran R, Tillman H, Kim M, Connelly JP, et al: MAGE cancer-testis antigens protect the mammalian germline under environmental stress. Sci Adv 5: eaav4832, 2019.

14. Zhang Y,Zhang Y and Zhang L: Expression of cancer-testis antigens in esophageal cancer and their progress in immunotherapy. J Cancer Res Clin Oncol 145: 281-291, 2019.

15. Sang M, Meng L, Sang Y, Liu S, Ding P, Ju Y, Liu F, Gu L, Lian Y, Li J, et al: Circular RNA ciRS-7 accelerates ESCC progression through acting as a miR-876-5p sponge to enhance MAGE-A family expression. Cancer Lett 426: 37-46, 2018.

16. Lee TB, Lim SC, Moon YS and Choi CH: Melanoma antigen gene family $\mathrm{A}$ as a molecular marker of gastric and colorectal cancers. Oncol Rep 30: 234-238, 2013

17. Guo JC, Yang YJ, Zhang JQ, Guo M, Xiang L, Yu SF, Ping H and Zhuo L: microRNA-448 inhibits stemness maintenance and self-renewal of hepatocellular carcinoma stem cells through the MAGEA6-mediated AMPK signaling pathway. J Cell Physiol 234: 23461-23474, 2019.

18. Shannon P, Markiel A, Ozier O, Baliga NS, Wang JT, Ramage D, Amin N, Schwikowski B and Ideker T: Cytoscape: A software environment for integrated models of biomolecular interaction networks. Genome Res 13: 2498-2504, 2003.

19. Jurisic V: Multiomic analysis of cytokines in immuno-oncology. Expert Rev Proteomics 17: 663-674, 2020.

20. Zou C, Shen J, Tang Q, Yang Z, Yin J, Li Z, Xie X, Huang G, Lev D and Wang J: Cancer-testis antigens expressed in osteosarcoma identified by gene microarray correlate with a poor patient prognosis. Cancer 118: 1845-1855, 2012.

21. Hilal NR, Novikov DV, Novikov VV and Karaulov AV: Cancer-testis genes in colon cancer. Ter Arkh 89: 113-117, 2017 (In Russian).

22. Bredenbeck A, Hollstein VM, Trefzer U, Sterry W, Walden P and Losch FO: Coordinated expression of clustered cancer/testis genes encoded in a large inverted repeat DNA structure. Gene 415: 68-73, 2008

23. Atanackovic D, Hildebrandt Y, Jadczak A, Cao Y, Luetkens T, Meyer S, Kobold S, Bartels K, Pabst C, Lajmi N, et al: Cancer-testis antigens MAGE-C1/CT7 and MAGE-A3 promote the survival of multiple myeloma cells. Haematologica 95: 785-793, 2010.

24. Zajac P, Schultz-Thater E, Tornillo L, Sadowski C, Trella E, Mengus C, Iezzi G and Spagnoli GC: MAGE-A antigens and cancer immunotherapy. Front Med (Lausanne) 4: 18, 2017.

25. Willett CS and Wilson EM: Evolution of melanoma antigen-A11 (MAGEA11) during primate phylogeny. J Mol Evol 86: 240-253, 2018

26. Tang WW, Liu ZH, Yang TX, Wang HJ and Cao XF: Upregulation of MAGEA4 correlates with poor prognosis in patients with early stage of esophageal squamous cell carcinoma. Onco Targets Ther 9: 4289-4293, 2016.

27. Meek DW and Marcar L: MAGE-A antigens as targets in tumour therapy. Cancer Lett 324: 126-132, 2012.

28. Laiseca JE, Ladelfa MF, Cotignola J, Peche LY, Pascucci FA, Castaño BA, Galigniana MD, Schneider C and Monte M: Functional interaction between co-expressed MAGE-A proteins. PLoS One 12: e0178370, 2017.

29. Yang P, Huo Z, Liao H and Zhou Q: Cancer/testis antigens trigger epithelial-mesenchymal transition and genesis of cancer stem-like cells. Curr Pharm Des 21: 1292-1300, 2015.

30. Tauber C, Schultheiss M, Luca R, Buettner N, Llewellyn-Lacey S, Emmerich F, Zehe S, Price DA, Neumann-Haefelin C, Schmitt-Graeff A, et al: Inefficient induction of circulating TAA-specific CD8+ T-cell responses in hepatocellular carcinoma. Oncotarget 10: 5194-5206, 2019.

31. Baran CA, Agaimy A, Wehrhan F, Weber M, Hille V, Brunner K, Wickenhauser C, Siebolts U, Nkenke E, Kesting M and Ries J: MAGE-A expression in oral and laryngeal leukoplakia predicts malignant transformation. Mod Pathol 32: 1068-1081, 2019.

32. Chen X, Cai S, Wang L, Zhang X, Li W and Cao X: Analysis of the function of MAGE-A in esophageal carcinoma by bioinformatics. Medicine (Baltimore) 98: e15774, 2019.

33. Ervin JM, Schütz LF and Spicer LJ: Current status of the role of endothelins in regulating ovarian follicular function: A review. Anim Reprod Sci 186: 1-10, 2017. 
34. Brancaccio M, Natale F, Falco G and Angrisano T: Cell-free DNA methylation: The new frontiers of pancreatic cancer biomarkers discovery. Genes (Basel) 11: 14, 2019.

35. Wiszniewski W, Hunter JV, Hanchard NA, Willer JR, Shaw C, Tian Q, Illner A, Wang X, Cheung SW, Patel A, et al: TM4SF20 ancestral deletion and susceptibility to a pediatric disorder of early language delay and cerebral white matter hyperintensities. Am J Hum Genet 93: 197-210, 2013.

36. Puissant MM, Muere C, Levchenko V, Manis AD, Martino P, Forster HV, Palygin O, Staruschenko A and Hodges MR: Genetic mutation of Kenj16 identifies Kir5.1-containing channels as key regulators of acute and chronic $\mathrm{pH}$ homeostasis. FASEB J 33: 5067-5075, 2019

37. Jabara HH, Boyden SE, Chou J, Ramesh N, Massaad MJ, Benson H, Bainter W, Fraulino D, Rahimov F, Sieff C, et al: A missense mutation in TFRC, encoding transferrin receptor 1 , causes combined immunodeficiency. Nat Genet 48: 74-78, 2016.

38. Sato Y, Inokuchi M, Takagi Y and Kojima K: IGFBP1 is a predictive factor for haematogenous metastasis in patients with gastric cancer. Anticancer Res 39: 2829-2837, 2019.
39. Andrew M, Liao L, Fujimoto M, Khoury J, Hwa V and Dauber A: PAPPA2 as a therapeutic modulator of IGF-I bioavailability: In vivo and in vitro evidence. J Endocr Soc 2: 646-656, 2018

40. Wu K, Li L, Li L and Wang D: Long non-coding RNA HAL suppresses the migration and invasion of serous ovarian cancer by inhibiting EMT signaling pathway. Biosci Rep 40: BSR20194496, 2020.

41. Jiang H, Liu Y, Qian Y, Shen Z, He Y, Gao R, Shen M, Chen S, Fu Q and Yang T: CHL1 promotes insulin secretion and negatively regulates the proliferation of pancreatic $\beta$ cells. Biochem Biophys Res Commun 525: 1095-1102, 2020.

(i) $\odot$ This work is licensed under a Creative Commons Attribution-NonCommercial-NoDerivatives 4.0 International (CC BY-NC-ND 4.0) License. 